\title{
Serotonin receptor modulation in irritable bowel syndrome: one step forwards and one step backwards
}

Camilleri M, Northcutt AR, Kong S, et al. Efficacy and safety of alosetron in women with irritable bowel syndrome: a randomised, placebo-controlled trial. Lancet 2000;355:1035-40.

\section{Question}

Does alosetron, 5- $\mathrm{HT}_{3}$ receptor antagonist, reduce symptoms in women with diarrhoea due to irritable bowel syndrome?

\section{Design}

Randomised, double blind controlled trial of 12 weeks' treatment.

\section{Setting}

One hundred nineteen sites in the USA consisting of outpatient clinics and clinical research centres.

\section{Patients}

A total of 647 of 1463 women screened, aged over 18 years, with at least six months of symptoms that fulfilled the Rome criteria for irritable bowel syndrome (IBS). Patients were classified as diarrhoea predominant or constipation predominant if one or the other was present for at least $75 \%$ of the time of active symptoms, and the remainder were classed as alternating IBS. Constipation predominant patients were excluded.

\section{Intervention}

After a two week screening period, patients were randomly allocated to $1 \mathrm{mg}$ of alosetron or placebo to be taken orally twice daily before meals for 12 weeks followed by four weeks of post-treatment follow up. Patients were seen monthly by their enrolling physician and symptom data were also collected daily using an electronic touch tone telephone and computer driven interview.

\section{Outcome measures}

The primary outcome was based on the response to the question "in the past seven days have you had adequate relief of your IBS pain and discomfort" and responders were defined as patients reporting adequate relief for at least two weeks per month - this level of relief having been prospectively agreed with a panel of IBS experts. Secondary end points included stool consistency, stool frequency, and urgency to defecate.

\section{Results}

Of 1463 patients screened, 816 were excluded mainly $(\mathrm{n}=686)$ because they did not meet the inclusion criteria: 324 were randomised to alosetron and 323 to placebo and all were included in an intention to treat analysis. In total, $24 \%$ of the alosetron group and $16 \%$ of the placebo group dropped out-10\% of the alosetron group withdrew because of constipation. The proportion of alosetron treated patients reporting adequate relief for all three months of treatment was $41 \%$ compared with $29 \%$ for those who received placebo (difference 12\%, 95\% confidence interval 4.7-19.2\%). Analysis of IBS subtype showed that adequate relief of pain and discomfort was confined to those with diarrhoea predominant IBS. Alosetron treatment was also found to decrease urgency and stool frequency, and increase stool firmness. Within three weeks of withdrawing treatment, symptoms had returned to baseline levels in both the alosetron and placebo groups. Constipation was the most common adverse event being reported by $30 \%$ of those taking alosetron compared with $3 \%$ of the placebo group. In all, $72 \%$ of the alosetron group and $65 \%$ of the placebo group reported at least one adverse event. No serious drug related adverse events were reported.

\section{Conclusion}

Alosetron was well tolerated and was effective in alleviating pain and bowel disturbance in women with diarrhoea due to IBS, but on cessation symptoms returned rapidly.

\section{Comment}

The pharmacological treatment of irritable bowel syndrome (IBS) is currently far from satisfactory and there have been no new drug developments for many years. Recently, there has been a surge of interest in serotonin and the gut with particular emphasis, where IBS is concerned, on $5-\mathrm{HT}_{3}$ and $5-\mathrm{HT}_{4}$ receptors. A number of agonists and antagonists of these receptors are now under investigation and alosetron (a 5- $\mathrm{HT}_{3}$ antagonist) was the first to reach the market in the USA.

In the study reported here which was confined to women, alosetron was found to be significantly superior to placebo in providing "adequate relief of pain/discomfort" in patients with diarrhoea and improving bowel function in patients with both diarrhoea and an alternating bowel habit. A particularly noteworthy feature was that the advantage of alosetron was promptly lost when treatment was stopped, suggesting a real effect. The main side effect of treatment was constipation but one case of ischaemic colitis was also reported.

IBS is notorious for its disparate symptomatology ${ }^{1}$ and the varying importance that patients place on a particular symptom. ${ }^{2}$ Thus defining a primary outcome measure for trials is fraught with difficulties, an issue which has recently been addressed by the Rome II Consensus Conference. ${ }^{3}$ It was suggested that a global outcome measure that integrates the key symptoms is probably the most preferable. Thus the "adequate relief of pain/discomfort" 
used in this study does not quite meet this standard but this trial was designed before the publication of Rome II.

Clinical trials in IBS have to have strict entry criteria and thus are only conducted on a small sample of patients. For instance, in this study, nearly half of the patients considered for entry were not eligible for randomisation. Thus trials such as these are undertaken on the "tip of the IBS iceberg" and very different results, which could be better or worse, may be forthcoming when the drug reaches the market place.

It is likely that new drug developments, as in this case, are likely to be directed to particular subgroups of the disorder. This is a crucial point as generations of doctors are used to prescribing the currently available medications to all forms of IBS without having to think about targeting symptoms. Thus there could be a temptation to try any new drug on "all comers". This could prove to be a major problem with the 5- $\mathrm{HT}_{3}$ antagonists where even in the carefully controlled conditions of a trial they caused constipation in $30 \%$ of patients. It is therefore vital that the pharmaceutical companies carefully address the issue of inappropriate prescribing which could lead to potentially serious consequences. Fortunately, this is unlikely to be a major problem for drugs that enhance transit, such as the $5-\mathrm{HT}_{4}$ agonists, where further loosening of an already loose bowel habit should not be too troublesome. We will also need to know much more about the gender effects of these drugs as there will be a strong temptation to try them in men. In addition, it will be interesting to see if there are any subtle differences in the activities of apparently similar $5-\mathrm{HT}_{3}$ antagonists and $5-\mathrm{HT}_{4}$ agonists which might be clinically exploitable.

Although IBS can severely impair quality of life, ${ }^{4}$ it is not a life threatening condition and therefore any potential new medication has to be much safer than might be acceptable for other indications. In addition, all new drugs are likely to be more expensive and thus increase the costs of treating IBS. Authorities are therefore likely to require evidence of superiority over existing drugs in addition to placebo and, where $5-\mathrm{HT}_{3}$ antagonists are concerned, may even demand comparisons with low dose tricyclic antidepressants which are being used increasingly in diarrhoea predominant IBS.

Unfortunately, alosetron has recently been withdrawn from the market in the USA because of further cases of ischaemic colitis. It remains to be determined whether this is a side effect confined to alosetron or represents a class effect common to all $5-\mathrm{HT}_{3}$ antagonists. If it is the latter, then this could present problems for all of the other $5-\mathrm{HT}_{3}$ antagonists in development. So far, no such similar adverse events have been reported for drugs active on the $5-\mathrm{HT}_{4}$ receptor.

P J WHORWELL Department of Medicine, University Hospital of South Manchester, Manchester, UK peter.whorwell@smuht.nwest.nhs.uk

Conflict of interest. Dr Whorwell acts as an adviser to a number of pharmaceutical companies, including GlaxoWellcome, Novartis, Smithkline Beecham, and Solvay Pharmaceuticals.

1 Whorwell PJ, McCallum M, Creed FH, et al. Non-colonic features of irritable bowel syndrome. Gut 1986;27:37-40.

2 Maxton DG, Morris JA, Whorwell PJ. Ranking of symptoms by patients with the irritable bowel syndrome. BMF 1989;299:1138.

3 Veldhuyzen van Zanten SJO, Talley NJ, Bytzer P, et al. Design of treatment trials for functional gastrointestinal disorders. Gut 1999;45(suppl II):116975 .

4 Wells NE, Hahn BA, Whorwell PJ. Clinical economics review: irritable bowel syndrome. Aliment Pharmacol Ther 1997;11:1019-30.

\section{Narrative Based Medicine, An Interdisciplinary Conference}

Research, Narrative, and Practice

A two day conference-Monday 3rd and Tuesday 4th September 2001

Homerton College, Cambridge, UK

BMF Publishing Group

For full details contact: BMA/BMJ Conference Unit, Tavistock Square, London, WC1H 9JP Tel: +44 (0)20 7383 6819; fax: +44 (0)20 7383 6663; email: clyders@bma.org.uk. www.quality.bmjpg.com 